\title{
TRATATIVA CONSTITUCIONAL DE LOS DERECHOS CULTURALES COMO CATEGORÍA DE DERECHOS HUMANOS en el PeRÚ
}

\author{
Daniel Arnaldo Zegarra Rivera* \\ Investigador independiente \\ dzegarra.rivera@gmail.com \\ Recibido: 2/1/2021 Aprobado: 9/1/2021 \\ doi: https://doi.org/10.26439/iusetpraxis2021.n052.5060
}

\begin{abstract}
RESUMEN. El presente estudio tiene como objetivo central determinar cómo ha sido el desarrollo de la tratativa constitucional de los derechos culturales como categoría de derechos humanos en el Perú. Se revisaron los principales instrumentos internacionales de los cuales surgen estos derechos para identificarlos y clarificarlos. Se comprobó que era necesario revisar las dos últimas cartas magnas peruanas (la Constitución de 1979 y su sucesora, la Constitución Política de 1993, vigente hasta la actualidad), pues ambas trataron los derechos culturales entendidos como derechos fundamentales, pero una y otra presentan diferencias no menores en cuanto al abordaje de estos derechos. Los resultados, en términos generales, fundamentaron que se ha operado un desarrollo positivo de la tratativa constitucional de los derechos culturales como categoría de derechos humanos en el Perú, y que los derechos culturales devenidos de la fuente constitucional son estos: identidad cultural, educación y formación cultural, información y comunicación, patrimonio cultural, expresiones culturales, creación cultural y cooperación cultural.
\end{abstract}

PALABRAS CLAVE: Constitución / derechos culturales / derechos humanos

\footnotetext{
* Abogado. Magíster en Derecho Constitucional, con estudios concluidos de maestría en Gestión y Políticas Públicas, por la Universidad Privada de Tacna. Especialista en Derecho Cultural y Derecho del Patrimonio Cultural. Actualmente, es subdirector de la Subdirección Desconcentrada de Patrimonio Cultural, Industrias Culturales e Interculturalidad de la Dirección Desconcentrada de Cultura de Tacna, Ministerio de Cultura.
} 


\section{CONSTITUTIONAL TREATMENT OF CULTURAL RIGHTS AS A CATEGORY OF HUMAN RIGHTS IN PERU}

ABSTRACT. The central objective of this study is to determine how the constitutional treatment of cultural rights has developed as a category of human rights in Peru. The main international instruments from which these rights arise were reviewed to identify and clarify them. The necessity to review the last two Peruvian Magna Cartas (the 1979 Political Constitution and its successor, the 1993 Political Constitution, which is currently in force) was determined since both of them address the cultural rights as fundamental rights, thus denoting significant differences regarding the approach to said rights. The results, in general terms, established that the constitutional treatment of cultural rights as a category of human rights in Peru has developed positively, and that the cultural rights coming from the Constitution are: cultural identity, cultural education and training, information and communication, cultural heritage, cultural expression, cultural creation and cultural cooperation.

KEYWORDS: Constitution / cultural rights / human rights 


\section{INTRODUCCIÓN}

En el mundo actual, la cultura (o lo cultural) ocupa un lugar tan importante que nadie podría negar su condición de factor determinante en el desarrollo de las personas tanto individual como colectivamente. Por ello, algunos autores piden para la cultura el cuarto lugar, si no el primero, entre los elementos integrantes del Estado contemporáneo (junto al poder, territorio y pueblo, según Jellinek) (Arroyo, 2006). "Los derechos culturales -que corresponden a una categoría particular de los derechos humanos-desempeñan un rol fundamental, en tanto se definen como el derecho de toda persona a tomar parte libremente en la vida cultural de la comunidad" (Organización de las Naciones Unidas [ONU], 2009), pues, siempre que una persona goce de estos derechos, poseerá mayores garantías y posibilidades de realización como individuo y junto a la sociedad de la que forma parte.

Para López (1999), como resultado de su reconocimiento por el derecho internacional como categoría de derechos humanos, "surgió la innegable responsabilidad de los Estados de introducir en sus textos constitucionales los derechos culturales y su compromiso de adoptar las medidas necesarias para su conservación, desarrollo y difusión, propiciando lo que ahora se conoce como Constitución cultural" (p. 110).

Sin perjuicio de ello, en el caso de América Latina, se afronta una situación paradójica. De acuerdo con Mejía (2004), si bien ha ocurrido un enorme avance en cuanto al constitucionalismo cultural, esta realidad no guarda relación con la vigencia y el ejercicio efectivo de los derechos culturales (como se citó en Bayardo, 2010, p. 59). Por esa conclusión, se constata un fuerte deterioro de la institucionalidad que da pie a que, más allá de las buenas intenciones establecidas en las constituciones, "la efectivización [sic] de los derechos culturales esté muy lejos de ser un hecho, debido, entre otros factores, a las dificultades de definir políticas nacionales, regionales o locales que tengan como base los derechos culturales" (Bayardo, 2010, p. 60).

En este artículo se muestra un estado de la cuestión respecto a cómo se ha desarrollado la tratativa constitucional de los derechos culturales como categoría de derechos humanos en el Perú. Para lograr este objetivo, se lleva a cabo una revisión profunda de las Constituciones Políticas de 1933, 1979 y 1993 a fin de dilucidar qué derechos culturales propugnó cada una de ellas, cómo los consignaron y si lograron -en sus respectivos períodos de vigencia- servir de sustento para propiciar la búsqueda del posicionamiento conceptual y procedimental de los derechos culturales como categoría de derechos humanos en nuestro país.

Este trabajo resulta de utilidad tanto para el campo académico como para el profesional. Para el primero, porque analiza los derechos culturales desde la perspectiva de los derechos fundamentales, tarea que siempre demanda mayores estudios. Y, para el 
segundo, porque los profesionales del derecho de cualquier nacionalidad podrán tomar esta investigación como punto de referencia para iniciar similares procesos en sus respectivos países.

A continuación, se explica el origen y la construcción del concepto de derechos culturales. Luego, se realiza un acercamiento al tratamiento que estos reciben en los instrumentos internacionales de ámbito universal y latinoamericano, así como por la Unesco y la Declaración de Friburgo. Después, se hará una revisión de la obligación de los Estados en cuanto a la aplicación, respeto, protección y cumplimiento de los derechos culturales. Seguidamente, se abordará los derechos culturales como categoría de derechos humanos en el constitucionalismo peruano, para proseguir con la constitucionalización de la cultura y la Constitución cultural del Perú. En este sentido, se trata a la Constitución Política de 1993 como sustento para el posicionamiento conceptual y procedimental de los derechos culturales: la ruta peruana hacia su fortalecimiento, reconocimiento y consolidación. Finalmente, se plantean las conclusiones de esta investigación.

\section{DERECHOS CULTURALES: ORIGEN Y CONSTRUCCIÓN DEL CONCEPTO}

\section{Origen: el marco histórico e internacional de los derechos humanos}

El reconocimiento de los derechos humanos ha experimentado una evolución que se remonta hasta los siglos XVIII y XIX. En una primera etapa, estuvieron circunscritos al reconocimiento de los derechos civiles, en cuanto derechos del individuo a una esfera cada vez más amplia de libertad individual (Harvey, 1995, p. 3). El proceso de gestación de las revoluciones políticas durante el siglo XVIII, que se extienden hasta nuestra época, eclosionó con la proclamación de la Declaración de Derechos de Virginia (1776) y de la Declaración de los Derechos del Hombre y del Ciudadano (1789) con el triunfo de la Revolución francesa. Esto trajo como consecuencia el reconocimiento de una dimensión nueva de derechos humanos: la de los derechos políticos del ciudadano (Harvey, 1995, p. 3). Harvey (1995) señala el siguiente punto sobre el concepto y evolución de los derechos humanos:

La declaración francesa señaló que la finalidad de toda sociedad política es la conservación de los derechos naturales e imprescriptibles del hombre. Estos derechos son la libertad, la seguridad y la resistencia a la opresión, proclamándose así derechos naturales del hombre, hoy calificados como civiles y políticos, junto a los principios básicos de libertad e igualdad ante la ley. Tal es el punto de partida de un proceso universal desarrollado ampliamente en los dos siglos anteriores y hasta la segunda década del siglo xx. (p. 3)

Posteriormente, y ya acabando la Primera Guerra Mundial, un movimiento generalizado que apuntaba al reconocimiento de una categoría más amplia de derechos inherentes a la persona, más allá de los derechos civiles y políticos, buscaba la proclamación de una 
segunda generación de derechos humanos: los económicos, sociales y culturales. Su consagración en las Constituciones Políticas de los Estados, a partir de la de los Estados Unidos Mexicanos (1917) y de la República de Weimar (1919), "permiten que pueda considerarse que estos derechos noveles alcanzasen verdadero estatuto jurídico-formal en los textos constitucionales" (De Castro, 1993, p. 53), lo que impulsó, tanto en el orden jurídico interno de los países como en el campo de las relaciones internacionales, un movimiento universal a su favor (Harvey, 1995, pp. 3-4).

Sin embargo, fue en el plano supraestatal donde se produjo, tras la finalización de la Segunda Guerra Mundial, la culminación de este proceso con la aprobación por la Asamblea de las Naciones Unidas de la Declaración Universal de Derechos Humanos (1948), la cual, junto a los tradicionales derechos civiles y políticos, proclamó los flamantes derechos económicos, sociales y culturales. Las Constituciones Políticas de los Estados, a partir del fin de la Segunda Guerra Mundial, intensificaron el reconocimiento nacional de los nuevos derechos (Harvey, 1995). Es importante referir que los derechos económicos, sociales y culturales, necesarios para el pleno desarrollo de la personalidad de cada ser humano, tienen como característica que, a diferencia de los civiles y políticos, "se realizan a través o por medio del Estado" (Harvey, 1995, p. 4), que actúa así como "instrumentos para el bienestar de todas las personas dependientes de su jurisdicción, que les permitiera desarrollar al máximo sus facultades individual o colectivamente" (Van Boven, 1984, p. 136).

\section{Construcción del concepto: rumbo a una definición de derechos culturales}

Aunque, como afirma Niec (1998), definir los derechos culturales se presenta como una tarea monumental, no cabe duda de que forman parte de la categoría de derechos "más emblemática respecto a las divisiones ideológicas en materia de derechos humanos cristalizadas después de la Segunda Guerra Mundial" (Champeil-Desplats, 2010, p. 94) y de que, a pesar de que cada día gozan de mayor peso en la conciencia general de los derechos humanos, aún no han alcanzado la misma importancia que el resto, ni en los programas políticos ni en los textos legales (Custodio, 2014, p. 15). Por este motivo, se ha dicho de ellos en múltiples ocasiones que son "una categoría descuidada de derechos humanos", si usamos la expresión entregada por Symonides (2010); o una "categoría subdesarrollada de los derechos humanos" (Meyer-Bisch, 1993), de acuerdo con el Grupo de Friburgo; o la no menos descriptiva expresión acuñada por el profesor Jesús Prieto de Pedro (2008), que los define como el "pariente pobre de los derechos humanos" (pp. 19-23).

A pesar de todo, en los últimos años, se han dado avances importantes en cuanto a su conceptualización. Entre estos esfuerzos, podemos destacar, por ejemplo, el que contiene la Carta Cultural Iberoamericana de Montevideo (Organización de Estados Americanos [OEA], 2006), la cual refiere que los derechos culturales deben entenderse 
como derechos de carácter fundamental, según los principios de la universalidad, indivisibilidad e interdependencia. Su ejercicio encuentra desarrollo en el marco del carácter integral de los derechos humanos, de forma tal que ese mismo ejercicio permite y facilita a todos los individuos y grupos la realización de sus capacidades creativas, así como el acceso, la participación y el disfrute de la cultura. Estos derechos son la base de la plena ciudadanía y hacen de los individuos, en el colectivo social, los protagonistas del quehacer en el campo de la cultura (OEA, 2006, p. 7).

Con el mismo espíritu, Prieto de Pedro (2008) ha señalado que una concepción integral de los derechos culturales debería contemplar la totalidad de los derechos que se relacionan con los procesos culturales, comprendiendo así a las libertades de creación artística, científica y de comunicación social; los derechos de autor; el derecho de acceso a la cultura; el derecho a la identidad y a la diferencia cultural; y el derecho a la conservación cultural (pp. 20-21). Esta catalogación guarda vínculos con la presentada por Stamatopoulou-Robbins (2008), quien indica que son generalmente cinco los entendidos como derechos culturales:

El derecho de educación; el derecho a participar en la vida cultural; el derecho de disfrutar de los beneficios del progreso científico y sus aplicaciones; el derecho de beneficiarse de la protección de los intereses morales y materiales que le correspondan por razón de las producciones científicas, literarias o artísticas de que sea autor; $y$, finalmente, la libertad para la investigación científica y la actividad creativa. (p. 3)

Por último, no puede dejarse de lado el análisis conceptual del adjetivo cultural que delimita estos derechos y que, además, conlleva su propia problemática (Custodio, 2014, p. 18) en cuanto a su definición. Pero, sin perjuicio de ella, cultura puede referirse a muchas cosas, desde el cultivo de las ciencias y disciplinas del conocimiento, incluidas las artes y las letras, hasta un proceso integral asociado a las formas de vida (Donders, 2004). Se entiende por cultura al conjunto complejo de conocimientos, creencias, artes, moral, leyes, costumbres y usos sociales que el ser humano adquiere como miembro de una sociedad determinada (Häberle, 2000, p. 145).

\section{LOS DERECHOS CULTURALES EN LOS PRINCIPALES INSTRUMENTOS INTERNACIONALES}

Ha quedado claro que los derechos culturales han surgido desde el seno de los derechos humanos. Son parte de ese sistema con criterios y principios de peso significativo, que bien podrían guiar las normas que pretenden regular los países respecto de estos derechos (Mesinas, 2017, p. 234). En consecuencia, es indispensable revisar los principales instrumentos internacionales de los cuales provienen. 


\section{Instrumentos internacionales de ámbito universal (ONU)}

\section{Declaración Universal de Derechos Humanos (1948)}

El primer instrumento aprobado por la Organización de las Naciones Unidas en el que se enumeran los derechos culturales es la Declaración Universal de Derechos Humanos (1948). Es su punto de partida. El artículo 27 de la declaración contiene referencias explícitas a estos derechos:

1. Toda persona tiene derecho a tomar parte libremente en la vida cultural de la comunidad, a gozar de las artes y a participar en el progreso científico y en los beneficios que de él resulten.

2. Toda persona tiene derecho a la protección de los intereses morales y materiales que le correspondan por razón de las producciones científicas, literarias o artísticas de que sea autora.

Debe considerarse también el artículo 10, que versa sobre el derecho a la información; el artículo 22, relacionado a la satisfacción de los derechos culturales indispensables a la dignidad y libre desarrollo de la personalidad; y el artículo 26 , que trata el derecho a la educación. (ONU, 1948, p. 8)

\section{Pacto Internacional de Derechos Económicos, Sociales y Culturales (1966)}

El Pacto Internacional de Derechos Económicos, Sociales y Culturales de la Organización de las Naciones Unidas (1966) en su artículo 15 considera:

1. Los Estados Partes en el presente Pacto reconocen el derecho de toda persona a: a) participar en la vida cultural; b) gozar de los beneficios del progreso científico y de sus aplicaciones; c) beneficiarse de la protección de los intereses morales y materiales que le correspondan por razón de las producciones científicas, literarias o artísticas de que sea autora.

2. Entre las medidas que los Estados Partes en el presente Pacto deberán adoptar para asegurar el pleno ejercicio de este derecho, figurarán las necesarias para la conservación, el desarrollo y la difusión de la ciencia y de la cultura.

3. Los Estados Partes en el presente Pacto se comprometen a respetar la indispensable libertad para la investigación científica y para la actividad creadora.

4. Los Estados Partes en el presente Pacto reconocen los beneficios que derivan del fomento y desarrollo de la cooperación y de las relaciones internacionales en cuestiones científicas y culturales. (ONU, 1966, p. 6)

A ello debe agregarse el artículo 13 referido a la educación. 
Pacto Internacional de Derechos Civiles y Políticos (1966)

En cuanto a este instrumento, para algunos autores solo contiene una referencia a los derechos culturales en su artículo 27, mediante el cual garantiza a las minorías étnicas, religiosas o lingüísticas el derecho que les corresponde en común con los demás miembros de su grupo a tener su propia vida cultural, a profesar y practicar su propia religión, y a emplear su propio idioma. Sin embargo, considero necesario agregar el artículo 19, dentro del contexto del derecho a la libertad de opinión y expresión.

\section{Instrumentos internacionales de ámbito americano (OEA)}

\section{Carta de la Organización de Estados Americanos (1948)}

La Carta de la Organización de Estados Americanos (1948) posee varios artículos que se vinculan a los derechos culturales. Entre ellos destaca el artículo 50, que establece que “los Estados miembros asegurarán [...] el goce de los bienes de la cultura a la totalidad de la población, y promoverán el empleo de todos los medios de difusión para el cumplimiento de estos propósitos" (OEA, 1948, p. 7).

\section{Declaración Americana de los Derechos y Deberes del Hombre (1948)}

En su artículo XIII consagra el derecho a los beneficios de la cultura, indicando que toda persona tiene el derecho de participar en la vida cultural de la comunidad, gozar de las artes y disfrutar de los beneficios que resulten de los progresos intelectuales y especialmente de los descubrimientos científicos (OEA, 30 de abril de 1948). Considero pertinente agregar el artículo XII, que se refiere al derecho a la educación.

Protocolo adicional a la Convención Americana sobre Derechos Humanos en Materia de Derechos Económicos, Sociales y Culturales "Protocolo de San Salvador" (1989)

En su artículo 14, se consagran el derecho a los beneficios de la cultura y la obligación de los Estados Partes a reconocerlos a toda persona.

\section{Unesco}

La labor de la Organización de las Naciones Unidas para la Educación, la Ciencia y la Cultura (Unesco) ha tenido especial alcance con los derechos culturales y su fortalecimiento. Como órgano especializado de la ONU, ha generado un nutrido número de instrumentos internacionales que promueven el desarrollo dogmático de los derechos culturales. Veamos, por ejemplo, la Declaración de la Diversidad Cultural (Unesco, 2001), instrumento que enumera derechos que pueden ser desarrollados como culturales en su artículo 5 (Mesinas, 2017, p. 238): 
Los derechos culturales son parte integrante de los derechos humanos, que son universales, indisociables e interdependientes. El desarrollo de una diversidad creativa exige la plena realización de los derechos culturales, tal como los define el artículo 27 de la Declaración Universal de Derechos Humanos y los artículos 13 y 15 del Pacto Internacional de Derechos Económicos, Sociales y Culturales. Toda persona debe tener la posibilidad de expresarse, crear y difundir sus obras en la lengua que desee y en particular en su lengua materna; toda persona tiene derecho a una educación y una formación de calidad que respeten plenamente su identidad cultural; toda persona debe tener la posibilidad de participar en la vida cultural que elija y conformarse a las prácticas de su propia cultura, dentro de los límites que impone el respeto de los derechos humanos y de las libertades fundamentales.

\section{Declaración de Friburgo (2007)}

Se trata de un proyecto de declaración sobre derechos culturales presentado el 7 de mayo del 2007 en la Universidad de Friburgo, cuya aprobación por la Asamblea General de la Unesco se encuentra pendiente hasta la fecha. Su importancia radica en que reúne y hace explícitos los derechos culturales que ya están incorporados, aunque en forma dispersa, en numerosos instrumentos internacionales (Colombato, 2012, p. 94). Según la Declaración de Friburgo (2007), los derechos culturales son y se definen:

1. Identidad y patrimonio culturales

Toda persona, individual o colectivamente, tiene derecho:

a. A elegir y a que se respete su identidad cultural, en la diversidad de sus modos de expresión. Este derecho se ejerce, en especial, en conexión con la libertad de pensamiento, conciencia, religión, opinión y de expresión.

b. A conocer y a que se respete su propia cultura, como también las culturas que, en su diversidad, constituyen el patrimonio común de la humanidad. Esto implica particularmente el derecho a conocer los derechos humanos y las libertades fundamentales, valores esenciales de ese patrimonio.

c. A acceder, en particular a través del ejercicio de los derechos a la educación y a la información, a los patrimonios culturales que constituyen expresiones de las diferentes culturas, así como recursos para las generaciones presentes y futuras.

\section{Referencia a comunidades culturales}

a. Toda persona tiene la libertad de elegir de identificarse, o no, con una o varias comunidades culturales, sin consideración de fronteras, y de modificar esta elección.

b. Nadie puede ser obligado a identificarse o ser asimilado a una comunidad cultural contra su voluntad. 
3. Acceso y participación en la vida cultural

a. Toda persona, individual y colectivamente, tiene el derecho de acceder y participar libremente, sin consideración de fronteras, en la vida cultural a través de las actividades que libremente elija.

b. Este derecho comprende en particular:

- La libertad de expresarse, en público o en privado, en el o los idiomas de su elección.

- La libertad de ejercer, de acuerdo con los derechos reconocidos en la presente declaración, las propias prácticas culturales, y de seguir un modo de vida asociado a la valorización de sus recursos culturales, en particular en lo que atañe a la utilización, la producción y la difusión de bienes y servicios.

- La libertad de desarrollar y compartir conocimientos, expresiones culturales, emprender investigaciones y participar en las diferentes formas de creación y sus beneficios.

- El derecho a la protección de los intereses morales y materiales relacionados con las obras que sean fruto de su actividad cultural.

\section{Educación y formación}

En el marco general del derecho a la educación, toda persona, individual o colectivamente, tiene derecho, a lo largo de su existencia, a una educación y a una formación que, respondiendo a las necesidades educativas fundamentales, contribuyan al libre y pleno desarrollo de su identidad cultural, siempre que se respeten los derechos de los demás y la diversidad cultural. Este derecho comprende en particular:

a. El conocimiento y el aprendizaje de los derechos humanos.

b. La libertad de dar y recibir una enseñanza de y en su idioma y de y en otros idiomas, al igual que un saber relacionado con su cultura y sobre las otras culturas.

c. La libertad de los padres de asegurar la educación moral y religiosa de sus hijos, de acuerdo con sus propias convicciones, siempre que se respeten la libertad de pensamiento, conciencia y religión reconocidas al niño, en la medida de la evolución de sus facultades.

d. La libertad de crear, dirigir y de acceder a instituciones educativas distintas de las públicas, siempre que estas respeten en conformidad con las normas y principios internacionales fundamentales en materia de educación y las reglas mínimas prescritas por el Estado en materia de educación reconocidas internacionalmente y prescritas en el marco nacional.

5. Información y comunicación

En el marco general del derecho a la libertad de expresión, que incluye la expresión artística, la libertad de opinión e información, y el respeto a la diversidad 
cultural, toda persona, individual o colectivamente, tiene derecho a recibir una información libre y pluralista, que contribuya al desarrollo pleno libre y completo de su identidad cultural en el respeto de los derechos del otro y de la diversidad cultural; este derecho, que se ejerce sin consideración de fronteras, comprende en particular:

a. La libertad de buscar, recibir y transmitir información.

b. El derecho de participar en la información pluralista, en el o los idiomas de su elección, de contribuir a su producción o a su difusión a través de todas las tecnologías de la información y de la comunicación.

c. El derecho de responder y, en su caso, de obtener la rectificación de las informaciones erróneas acerca de las culturas, siempre que se respeten los derechos enunciados en la presente declaración.

6. Cooperación cultural

Toda persona, individual o colectivamente, tiene derecho a participar, por medios democráticos, en el desarrollo cultural de las comunidades a las que pertenece; en la elaboración, la puesta en práctica y la evaluación de las decisiones que la conciernen y que afectan el ejercicio de sus derechos culturales; y en el desarrollo y la cooperación cultural en sus diferentes niveles. (pp. 5-8)

Custodio (2014) destaca en la Declaración de Friburgo la siguiente relevancia sobre los derechos mencionados:

La Declaración de Friburgo es un instrumento de gran utilidad para la identificación y delimitación de los derechos culturales, además de hacer una importante referencia sobre el rol que tienen en los diversos ámbitos como la prevención de guerras, violencia y terrorismo, así como en la educación, la diversidad y la identidad cultural. (p. 49)

\section{OBLIGACIÓN ESTATAL EN CUANTO A LA APLICACIÓN, RESPETO, PROTECCIÓN Y CUMPLIMIENTO DE LOS DERECHOS CULTURALES}

Los derechos humanos se ejercen erga omnes, por lo que generan obligaciones para y respecto de todas las personas. Desde la perspectiva del derecho internacional de los derechos humanos, son los Estados los principales obligados y garantes. El Pacto Internacional de Derechos Económicos, Sociales y Culturales expresa que las obligaciones estatales consisten en adoptar medidas hasta el máximo de los recursos disponibles y destinarlos al logro progresivo de su plena efectividad (artículo 2, inciso primero). Literalmente, se enfatiza el aspecto progresivo de estos derechos, pero una adecuada interpretación general ha de asumir que todo derecho reconocido como esencial al ser humano involucra obligaciones de los Estados para observarlos y asegurar un nivel de satisfacción mínimo (Muñoz, 2018, p. 91). El concepto de derechos humanos 
presupone la existencia de deberes paralelos de los Estados de aplicarlos; sin estas obligaciones, los derechos humanos $-\mathrm{y}$, en consecuencia, los derechos culturales - no tendrían sentido (Symonides, 2010).

En este camino, la Comisión Mundial de Cultura y Desarrollo (UDSE), en su informe titulado Nuestra diversidad creativa (1996), propuso una serie de medidas, entre ellas, la elaboración de un inventario de derechos culturales, toda vez que la necesidad de su "codificación" no está en tela de juicio, como tampoco lo está el hecho de que no hace falta crear nuevos derechos, sino dilucidar, clarificar y preparar una lista completa de los existentes ya proclamados. Sin embargo, para que todo esto funcione, es necesario el cumplimiento de aquello que un buen número de instrumentos normativos aprobados por las Naciones Unidas, la Unesco y las organizaciones regionales resaltan: la obligación de los Estados de aplicar los derechos culturales a través de todos los medios apropiados de los que pudieran servirse, además de adoptar las medidas legislativas, administrativas, financieras, educativas, sociales y de cualquier índole que resultasen necesarias para alcanzar este objetivo. En este proceso los Estados deben reconocer que primero deben crear las condiciones y proveer las garantías para la aplicación de los derechos culturales (Symonides, 2010).

Con el objetivo de trazar acciones concretas para impulsar en los Estados la ejecución de acciones garantistas, el Comité de Derechos Económicos, Sociales y Culturales impulsa el triple esquema de obligaciones: respeto, protección y cumplimiento (Muñoz, 2018, p. 91) que, si bien originalmente se orienta al derecho de participar en la vida cultural, considero que la luz tutelar de este triple esquema puede, sin inconvenientes, proyectarse hacia todos los derechos culturales. La perspectiva es que, con la implementación de este esquema, cuando menos, se logre el mínimo nivel de satisfacción pretendido; a contrario sensu, los derechos culturales estarían vaciados de contenido, alejados de su aplicación práctica, y pasarían a ser meros enunciados teóricos.

La obligación de respeto convoca al Estado para que se abstenga de interferir, directa o indirectamente, en la esfera de la libertad de participación en la vida cultural, ya sea individual o colectivamente. Esta obligación, en buena cuenta, pretende el respeto incluso de otras libertades, como las de opinión, expresión, información y creación, y, en general, de todos los derechos culturales. La obligación de protección requiere que los Estados adopten medidas positivas para impedir la intervención de otros agentes en el ejercicio de los derechos culturales que eviten o dificulten su disfrute. Y, por último, la obligación de cumplimiento o satisfacción exige del Estado la adopción de medidas activas (legislativas, administrativas, judiciales, presupuestarias y de promoción) que provean condiciones para una amplia participación en la vida cultural por parte de todas las personas (Muñoz, 2018, pp. 91-92), así como garantizar con similares herramientas el resto de sus derechos culturales. Dentro de este último marco (obligación de cumplimiento), las políticas públicas culturales cumplen uno de los roles más importantes, pero 
son un verdadero desafío para el conjunto de las políticas culturales de los Estados, dado que estas usualmente han estado centradas en "edificar nación", como sostiene el informe Nuestra diversidad creativa (UDSE, 1996). Lo descrito genera, al menos, dos problemas: "el del reconocimiento y la puesta en práctica de políticas culturales, y el de la vigencia y efectivización [sic] de los derechos culturales de las personas como individuos y colectivamente" (Bayardo, 2010, p. 55).

En América Latina, según Mejía (2004), afrontamos una situación paradójica: la circunstancia de un enorme avance en cuanto al constitucionalismo cultural, que no guarda relación alguna con la vigencia y el ejercicio efectivo de los derechos culturales (como se citó en Bayardo, 2010, p. 59). Es decir, se constata un fuerte deterioro de la institucionalidad que da pie a que, más allá de las buenas intenciones establecidas en las constituciones de cada país, la efectuación de los derechos culturales está muy lejos de ser un hecho en la mayoría de los casos. Esto se debe, entre otros factores, a las dificultades para definir políticas nacionales, regionales o locales que tengan como base los derechos culturales (Bayardo, 2010, p. 60).

\section{LOS DERECHOS CULTURALES COMO CATEGORÍA DE DERECHOS HUMANOS EN EL CONSTITUCIONALISMO PERUANO}

El análisis de cómo han sido abordados los derechos culturales como categoría de derechos humanos en el derecho constitucional peruano requiere, primero, definir qué buscamos entre las doce constituciones que el Perú ha tenido y, segundo, determinar desde cuándo buscamos. En cuanto al primer requerimiento (¿qué buscamos?), el catálogo de la Declaración de Friburgo es el que mejor ha logrado unificar los derechos culturales. Por tanto, para examinar la concreción de las referencias directas o indirectas a cultura/ derechos culturales en el articulado constitucional, usaré a modo de guía el listado contenido en la mencionada declaración. Respecto al segundo requerimiento (¿desde cuándo buscamos?), debe notarse que en los apartados previos se ha determinado que los derechos culturales como categoría de derechos humanos aparecieron concretamente después de la Segunda Guerra Mundial con la Declaración Universal de Derechos Humanos en 1948. En consecuencia, de las doce constituciones peruanas, corresponderá revisar solo aquellas que tuvieron vigencia desde 1948. Estas son la Constitución Política del Perú de 1933, la Constitución Política de 1979 y la actual Constitución de 1993.

\section{Constitución Política del Perú de 1933}

La Constitución de 1933 ha sido tomada en cuenta porque se encontraba en vigor cuando surgió la Declaración Universal de Derechos Humanos en 1948. Tuvo una vigencia de 32 años posteriores a ese evento internacional hasta su final derogación, ocurrida el 28 de julio de 1980, para dar paso a la Constitución Política de 1979. 
Esta Carta Magna, luego de la aprobación de la Declaración Universal, no tuvo ninguna reforma con el objetivo de permitir el ingreso de los derechos culturales. Por ello, con este dato, tendré por concluido su análisis. Corresponderá centrar esfuerzos tanto en la Constitución Política de 1979 como en la actual de 1993 para evaluar, en ambas, cómo ha sido y es la tratativa de los derechos culturales como categoría de derechos humanos.

\section{Constitución Política del Perú 1979}

Esta Constitución entró en vigor el 28 de julio de 1980 y fue un texto que para muchos juristas se inscribía en las modernas tendencias del constitucionalismo contemporáneo (Chanamé, 2015, p. 12). Cinco artículos de la Constitución de 1979 contenían expresamente el término cultura; sin embargo, poseía más apartados con garantías que por su contenido podría afirmarse que aludían a derechos culturales. Estos se encontraban repartidos en el Título I: Derechos y deberes fundamentales de la persona, específicamente entre el Capítulo I: De la persona y el Capítulo IV: De la educación, la ciencia y la cultura. Es importante destacar que esta Constitución posee un preámbulo extenso, pero con una sola referencia a los derechos culturales a través de la expresión del propósito estatal de defender el patrimonio cultural como medio para mantener y consolidar la personalidad histórica de la patria (Constitución Política de 1979, 1980, preámbulo).

Al analizar la concreción del articulado constitucional de 1979, se intuye -a la luz del listado presentado por la Declaración de Friburgo- cinco bloques de reunión, dentro de los cuales es posible ubicar los derechos culturales directa o indirectamente. Estos son identidad cultural, patrimonio cultural, acceso y participación en la vida cultural, educación y formación, e información y comunicación. A ellos se añade el bloque de cooperación cultural.

\section{Identidad cultural}

La Constitución de 1979 no contiene tutela expresa de la identidad cultural. Debe subsumirse en los incisos 3 y 4 del artículo 2, que versan sobre la libertad de conciencia y la libertad de expresión respectivamente. Sí regula la obligación de la enseñanza de los derechos humanos tanto en la educación civil como militar en todos sus niveles, en el artículo 22. Los artículos 34 y 35 también forman parte de este grupo, porque a través de ellos el Estado estimulaba la preservación de las manifestaciones culturales nativas y las lenguas aborígenes, innegables oportunidades identitarias.

Los artículos 161, 162 y 163 tenían como horizonte resguardar los derechos de las comunidades campesinas y nativas. Considero que estos artículos protegían la identidad cultural de estas comunidades, aunque no fuese una determinación expresa. 


\section{Patrimonio cultural}

Tutelado solo por el artículo 36, en este apartado se expresaba que los yacimientos y restos arqueológicos, construcciones, monumentos, objetos artísticos y testimonios de valor histórico, declarados Patrimonio Cultural de la Nación, estaban bajo el amparo del Estado. La ley regulaba su conservación, restauración, mantenimiento y restitución.

\section{Acceso y participación en la vida cultural}

Indirectamente, este derecho estaba resguardado por el inciso 4 del artículo 2. Y, directamente, en cuanto al acceso a la cultura, por la segunda parte del inciso 6 del artículo 2 y en el inciso 16 del mismo articulado respecto a participación cultural.

\section{Educación y formación}

El derecho a la educación es un marco general dentro del cual deben garantizarse condiciones que permitan a las personas alcanzar pleno desarrollo de su identidad cultural (Declaración de Friburgo, 2007, p. 7). Este marco general estaba dado -con caracteres que resultaban perfectibles- desde el artículo 21 hasta el artículo 40. En este grupo puede destacarse el artículo 21, que consideraba expresamente que el derecho a la educación y a la cultura es inherente a la persona humana y que la educación tiene como fin el desarrollo integral de la personalidad. El artículo 22 fijaba que la educación fomenta el arte y la ciencia, y que la educación religiosa se imparte sin vulnerar la libertad de conciencia. Además, determinaba la obligación de la enseñanza de los derechos humanos. Cabe destacar que esta Carta establecía como obligatoria solo a la educación primaria (artículo 25); la educación inicial y secundaria no tenían el mismo carácter. Este es un aspecto no menor, puesto que, aun cuando señalaba que mantenía su obligatoriedad en todas sus modalidades, resultaba una previsión insuficiente si el objetivo era garantizar a las personas contextos educativos que, respondiendo a las necesidades educativas fundamentales, contribuyeran al libre y pleno desarrollo de su identidad cultural.

\section{Información y comunicación}

Las referencias pueden entenderse subsumidas en los incisos 4 y 6 del artículo 2 de la Constitución de 1979.

\section{Cooperación cultural}

Si bien no existe referencia directa, considero que la existencia de libertades fundamentales posibilitaba la cooperación cultural, en tanto se la entiende como el derecho que toda persona tiene, individual o colectivamente, a participar por medios democráticos en el desarrollo cultural de las comunidades a las que pertenece y en la elaboración, la 
puesta en práctica y la evaluación de las decisiones que la conciernen y que afectan el ejercicio de sus derechos culturales (Declaración de Friburgo, 2007, p. 8)

\section{Constitución Política del Perú de 1993}

Esta Constitución entró en vigencia el 31 de diciembre de 1993 y, a diferencia de su antecesora, presenta un preámbulo reducido donde no hace ninguna referencia a cultura 0 derechos culturales.

Contiene siete artículos en los que menciona expresamente el término cultural cultural. A ello se suma otro grupo de preceptos que, directa o indirectamente, por su contenido, denotan y representan los derechos culturales. Estos derechos están repartidos entre el Título I: De la persona y la sociedad (donde ocupa lugares en el Capítulo I: Derechos fundamentales de la persona, el Capítulo II: De los derechos sociales y económicos, y el Capítulo VI: Del régimen agrario y de las comunidades campesinas y nativas), y en el Título IV: De la estructura del Estado (en el Capítulo XIV: De la descentralización). Con el objetivo de establecer una comparación didáctica con la Constitución de 1979, se usarán similares bloques de reunión de los derechos culturales contenidos en la Constitución de 1993.

\section{Identidad cultural}

Merece rescatarse como positiva la impronta étnica (Marzal, 1978) en la filosofía constitucional peruana de la Constitución de 1993. Así, aparte de reafirmar el derecho de toda persona a usar su lengua aborigen (segunda parte del inciso 19 del artículo 2), provee del derecho a la identidad étnica. Con ello se permitiría afirmar un Perú pluriétnico y multinacional (Cotler, 1987). Similar condición contiene el artículo 89, en tanto define que el Estado respeta la identidad cultural de las comunidades campesinas y nativas. El artículo 14 establece la obligatoriedad de la enseñanza de los derechos humanos. El artículo 17 contiene en su último párrafo una fórmula clara que fomenta la educación bilingüe e intercultural según las características de cada zona. No es menor la trascendencia de este artículo si tenemos en cuenta la diversidad cultural que caracteriza a la nación. La identidad cultural también se subsume en el inciso 1 del artículo 2, desarrollado con meritorio aporte por el descollante civilista Carlos Fernández Sessarego (1992). Finalmente, el artículo 48 supera la discriminación que existía en la Constitución de 1979 respecto a los idiomas oficiales, pues no solo sería el castellano, sino también el quechua, el aimara "y las demás lenguas aborígenes" (Zierer, 1992).

\section{Patrimonio cultural}

Tutelado por el artículo 21, determina que los yacimientos y restos arqueológicos, construcciones, monumentos, lugares, documentos bibliográficos y de archivo, objetos 
artísticos y testimonios de valor histórico, expresamente declarados bienes culturales, y provisionalmente los que se presumen como tales, son Patrimonio Cultural de la Nación, independientemente de su condición de propiedad privada o pública, y están protegidos por el Estado. Además, señala expresamente que la ley garantiza la propiedad de dicho patrimonio. Otro aspecto importante es que este artículo faculta al Estado a fomentar, conforme a ley, la participación privada en la conservación, restauración, exhibición y difusión del patrimonio cultural, así como su restitución al país cuando hubiere sido ilegalmente trasladado fuera del territorio nacional. Asimismo, en su artículo 195, considera como una de las competencias de los gobiernos locales la de desarrollar y regular actividades y/o servicios en materia de conservación de monumentos arqueológicos e históricos, lo que es una referencia clara a bienes integrantes del Patrimonio Cultural de la Nación.

\section{Acceso y participación en la vida cultural}

La Constitución de 1993 señala expresamente en el inciso 8 del artículo 2 que el Estado propicia el acceso a la cultura y fomenta su desarrollo y difusión. Similar claridad contiene el inciso 17 del mismo artículo 2, que considera como derecho fundamental de la persona el de participar, en forma individual o asociada, en la vida cultural de la nación.

\section{Educación y formación}

Siguiendo el esquema de valoración usado para la Constitución de 1979, que proviene de la Declaración de Friburgo, se reconoce previamente que el derecho a la educación es un marco general dentro del cual deben garantizarse condiciones que permitan a las personas, a lo largo de su existencia, alcanzar pleno desarrollo de su identidad cultural (Declaración de Friburgo, 2007, p. 7). En la Constitución de 1993, este marco avanza desde su artículo 13 hasta el 19. En este grupo, destaca el artículo 13, pues determina que la finalidad de la educación es el desarrollo integral de la persona, además de garantizar la libertad de enseñanza, así como el deber de los padres de educar a sus hijos y su derecho a escoger los centros educativos y participar en el proceso educativo. El artículo 14 establece la obligatoriedad de la enseñanza de los derechos humanos. El artículo 17 posee especial relevancia por dos factores: el primero, porque considera obligatorias la educación inicial, primaria y secundaria; y el segundo, porque contiene en su último párrafo una fórmula clara que fomenta la educación bilingüe e intercultural según las características de cada zona. Otro artículo relevante es el 18 , que señala como fin de la educación universitaria la difusión cultural.

\section{Información y comunicación}

Puede considerarse como garantía de este derecho el contenido de los incisos 4 y 6 del artículo 2. 


\section{Cooperación cultural}

Si bien no existe referencia directa, considero que la existencia de libertades fundamentales posibilita la cooperación cultural, en tanto se la entiende como el derecho que toda persona tiene, individual o colectivamente, a participar por medios democráticos en el desarrollo cultural de las comunidades a las que pertenece y en la elaboración, la puesta en práctica y la evaluación de las decisiones que la conciernen y que afectan el ejercicio de sus derechos culturales (Declaración de Friburgo, 2007, p. 8).

\section{CONSTITUCIONALIZACIÓN DE LA CULTURA Y CONSTITUCIÓN CULTURAL DEL PERÚ}

El fenómeno conocido como constitucionalización de la cultura es característico solo del constitucionalismo contemporáneo (López, 1999, p. 109). La cultura y los derechos culturales aparecen reflejados en la Carta Magna de los modernos Estados con conceptos complejos y ricos, como una realidad pluridimensional que implica derechos individuales, derechos colectivos y una trascendental y básica faceta de función social al servicio de la colectividad (Torres del Moral, 1984, p. 210). La constitucionalización de la cultura reconoce los derechos culturales (López, 1999, p. 109) y se define por la interpretación sistemática de todos los preceptos que se refieren a la realidad pluridimensional en que la cultura consiste (Tajadura, 1998, p. 102).

Al respecto, Torres del Moral (1984) escribe: "Generalmente, podríamos decir que en todo texto fundamental, al menos en el constitucionalismo más reciente, coexisten una Constitución política, una Constitución económica y una Constitución cultural" (p. 88). En efecto, al lado del conjunto de principios que la Constitución dedica, por ejemplo, a las relaciones económicas, deben situarse una serie de disposiciones de no menos trascendencia que den entrada a una nueva dimensión de garantías constitucionales cuyo fundamento se centra en una serie de opciones en las que se acepta determinado modelo de cultura, y que deben integrarse bajo la noción común de Constitución cultural (Pizzorusso, 1984, p. 193). Así como se habla de la Constitución económica, tenemos que referirnos a la Constitución cultural como el conjunto de principios y preceptos con relativa autonomía que se refieren a materias culturales (Miranda, 2010, p. 52).

Pero la expresión Constitución cultural debe ser tomada con prudencia. Considerar una Constitución cultural (o una Constitución económica, penal o electoral) puede revelarse útil, en la triple medida en que proporciona una conciencia más nítida del objeto de la Constitución, permite profundizar el análisis de las pertinentes normas constitucionales y sirve de apoyo para el imprescindible puente entre esas normas y las normas de la legislación ordinaria que la desarrollan. Sin embargo, todo esto no debe tener como consecuencia la eliminación y pérdida de la unidad sistemática de la Constitución. No existe una Constitución cultural independiente de la Constitución política o una Constitución penal al margen de la Constitución administrativa. Incluso cuando hubiera 
discrepancias entre ellas, deben ser leídas y comprendidas en el contexto de la misma Constitución material (Miranda, 2003, p. 289). Así el asunto, la Constitución cultural en el Perú está integrada por los siguientes preceptos: incisos 3, 4, 8, 17 y 19 del artículo 2; artículos 13, 14, 16, 17, 18, 19, 21, 48, 89, 190 y 195 de la Constitución Política de 1993.

\section{LA CONSTITUCIÓN POLÍTICA DE 1993 COMO SUSTENTO PARA EL POSICIONAMIENTO CONCEPTUAL Y PROCEDIMENTAL DE LOS DERECHOS CULTURALES}

Teniendo a la Constitución Política de 1993 como sustento, el Perú oficializó la aprobación de su Política Nacional de Cultura ${ }^{1}$ mediante el Decreto Supremo N. ${ }^{\circ}$ 009-2020-MC de fecha 20 de julio del 2020. Se trata de un instrumento que toma como punto de partida el reconocimiento de que el país presenta un grave problema vinculado a las limitaciones que tienen los ciudadanos para ejercer plenamente sus derechos culturales. Por esta razón, la política pública apuesta por reconocer y consolidar a los ciudadanos como sujetos de derechos culturales (Ministerio de Cultura, 2020, p. 8). Responde oficialmente a la pregunta: ¿qué son los derechos culturales? (p. 18); entrega una definición de cultura (p. 19) y responde a otra pregunta de no menor importancia: ¿cuáles son los derechos culturales de los peruanos? Estos se resumen en la tabla 1.

Tabla 1

Derechos culturales de los peruanos según la Política Nacional de Cultura (2020)

\begin{tabular}{|c|c|}
\hline Derecho cultural & Descripción \\
\hline Identidad cultural & $\begin{array}{l}\text { Toda persona tiene derecho a elegir y a que se respete su identidad cultural, en } \\
\text { la diversidad de sus modos de expresión (prácticas culturales, territorio, lengua, } \\
\text { etcétera), en conexión con la libertad de pensamiento, conciencia, religión, opinión } \\
\text { y de expresión. }\end{array}$ \\
\hline
\end{tabular}

(continúa)

1 Esta política se sustenta en la Constitución Política del Perú (1993), que señala que el Estado tiene el deber de reconocer y proteger la pluralidad étnica y cultural de la nación (artículo 2, numeral 19), proteger el Patrimonio Cultural de la Nación (artículo 21), y propiciar el acceso a la cultura y fomentar su desarrollo y difusión (artículo 2, numeral 8). En este sentido, el artículo 2 de la Constitución señala que toda persona tiene derecho "a la igualdad ante la ley" (numeral 2), "a las libertades de información, opinión, expresión y difusión del pensamiento mediante la palabra oral o escrita o la imagen, por cualquier medio de comunicación social, sin previa autorización ni censura ni impedimento algunos, bajo las responsabilidades de ley" (numeral 4); "a su identidad étnica y cultural" (numeral 8); "a participar, en forma individual o asociada, en la vida política, económica, social y cultural de la nación" (numeral 17), y "a la libertad de creación intelectual, artística, técnica y científica, así como a la propiedad sobre dichas creaciones y a su producto" (numeral 19) (Ministerio de Cultura, 2020, p. 10). 
(continuación)

$\begin{array}{ll}\text { Educación y } & \text { En el marco general del derecho a la educación, toda persona tiene derecho a una } \\ \text { formación cultural } & \text { educación y formación que contribuyan al libre y pleno desarrollo de su identidad } \\ & \text { cultural, siempre que se respeten los derechos de los demás y la diversidad cultural. } \\ & \text { En este orden de ideas, toda persona tiene derecho a: } \\ & \text { - El acceso y derecho a la formación en expresiones artísticas. } \\ & \text { - El conocimiento y el aprendizaje de los derechos culturales. } \\ & \text { - La libertad de dar y recibir una enseñanza de y en su idioma y de y en otros } \\ & \text { idiomas. } \\ & \text { - Conocer y comprender su propia cultura y la de otros. }\end{array}$

Informacióny En el marco general del derecho a la libertad de expresión, que incluye la de comunicación expresión artística, de opinión e información, y el respeto a la diversidad cultural, toda persona tiene derecho a recibir una información libre y pluralista, que contribuya al desarrollo pleno libre y completo de su identidad cultural en el respeto de los derechos de los demás y de la diversidad cultural. En este orden de ideas, toda persona tiene derecho a:

- La libertad de buscar, recibir y transmitir información libre y pluralista, en el o los idiomas de su elección.

- Conocer formas de expresión y difusión por cualquier medio tecnológico de información y comunicación.

- Responder y, en su caso, obtener la rectificación de las informaciones erróneas acerca de las culturas.

Patrimonio Comprende el derecho de toda persona a:

cultural - Aprovechar sosteniblemente los patrimonios culturales, haciendo uso de los mismos de acuerdo con su condición de bien cultural.

- Acceder, en particular a través del ejercicio de los derechos a la educación y a la información, a los patrimonios culturales.

- Conocer y a que se respete su propia cultura, como también las culturas que, en su diversidad, constituyen el patrimonio común de la humanidad.

\begin{tabular}{|c|c|}
\hline $\begin{array}{l}\text { Expresiones } \\
\text { culturales }\end{array}$ & $\begin{array}{l}\text { Comprende el derecho de toda persona a: } \\
\text { - Participar de los bienes, servicios y actividades que, considerados desde el punto } \\
\text { de vista de su calidad, utilización o finalidad específicas, encarnan o transmiten } \\
\text { expresiones culturales. } \\
\text { - Gozar de las artes y beneficiarse de las creaciones de otros individuos y } \\
\text { comunidades. } \\
\text { - Buscar, desarrollar y compartir con otros sus conocimientos y expresiones } \\
\text { culturales, emprender investigaciones, así como actuar con creatividad y } \\
\text { participar en las diferentes formas de creación y sus beneficios. }\end{array}$ \\
\hline Creación cultural & $\begin{array}{l}\text { Comprende el derecho de toda persona a: } \\
\text { - Contribuir a la creación de manifestaciones espirituales, materiales, intelectuales } \\
\text { y emocionales de la comunidad. } \\
\text { - La protección de los intereses morales y materiales relacionados con las obras } \\
\text { que sean fruto de su actividad cultural. } \\
\text { - La libertad de expresión y creación artística y el acceso a medios para su } \\
\text { expresión y difusión. } \\
\text { - Seguir un modo de vida asociado a la valorización de sus recursos culturales, en } \\
\text { particular en lo que atañe a la utilización, la producción y la difusión de bienes y } \\
\text { servicios. }\end{array}$ \\
\hline
\end{tabular}


(continuación)

\begin{tabular}{ll}
\hline $\begin{array}{l}\text { Cooperación } \\
\text { cultural }\end{array}$ & Comprende el derecho de toda persona a participar, por medios democráticos: \\
& - En el desarrollo cultural de las comunidades a las que pertenece. \\
& En la elaboración, la puesta en práctica y la evaluación de las decisiones que la \\
& conciernen y que afectan el ejercicio de sus derechos culturales. \\
& En el desarrollo y la cooperación cultural en sus diferentes niveles. \\
\hline
\end{tabular}

Fuente: Ministerio de Cultura (2020, pp. 20-21)

Opera, pues, a través de la visibilización y fortalecimiento de los derechos culturales en una política cultural, su posicionamiento conceptual y procedimental. El posicionamiento conceptual implica insertarlos en el discurso nacional y en el espacio público. El procedimental supone ubicarlos como fin y proceso en las intervenciones del Estado (Ministerio de Cultura, 2020, p. 18).

\section{CONCLUSIONES}

1. El desarrollo de la tratativa constitucional de los derechos culturales como categoría de derechos humanos en el Perú es positiva, sobre todo a la luz del contenido de la Constitución cultural de 1993 si la comparamos con su predecesora de 1979. Asimismo, esta posición se refuerza cuando se denota el rol fundamental protagonizado por la Carta Suprema vigente para la conformación de la lista de derechos culturales contenidos en la Política Nacional de Cultura (2020), la cual les otorga oficialidad, toda vez que forman parte de un instrumento de corte gubernamental y público, implementado por el Estado peruano.

2. Las Constituciones Políticas peruanas que han contenido derechos culturales son la Constitución de 1979 y la Constitución de 1993.

3. Los derechos culturales contenidos en las Constituciones Políticas peruanas son identidad cultural, patrimonio cultural, acceso y participación en la vida cultural, educación y formación, información y comunicación, y cooperación cultural.

4. Los derechos culturales fueron consignados en las constituciones peruanas de 1979 y 1993 con no menores diferencias en cuanto a su tratativa en cada una de ellas. Mientras que la Constitución de 1993, vigente en la actualidad, posee mayor claridad y eficiencia en cuanto a la redacción de los derechos culturales plasmados en su seno (directa e indirectamente), la Constitución de 1979, por su parte, carece de esas dos importantes cualidades en no pocos pasajes de su articulado cultural, además de no garantizar expresamente elementos tan importantes como, por ejemplo, el derecho a la identidad cultural, ausente en todas las líneas de esa Carta Suprema. La Carta de 1993 sí refiere este derecho 
de modo expreso. Con esto no pretendo afirmar que la Constitución cultural de 1993 no tenga artículos que deban revisarse, pues, en definitiva, contiene varios elementos sumamente perfectibles (algunos, incluso, de modo urgente); sin embargo, por la complejidad que comportan estos nuevos asuntos, considero que bien pueden ser materia de otra investigación.

5. Finalmente, concluyo que la Constitución de 1993 sí ha servido de sustento para propiciar la búsqueda del posicionamiento conceptual y procedimental de los derechos culturales como categoría de derechos humanos en el Perú. Esta función se concretó con el reconocimiento expreso de los derechos culturales y su descripción en la Política Nacional de Cultura (2020), instrumento que encontró fuerza en la Constitución de 1993, y que los ha referenciado, listado y descrito en un único instrumento con valor legal y carácter público-gubernamental. Las conclusiones de esta investigación permiten vislumbrar que, en algunos años, el Perú podría estar frente a un escenario distinto en cuanto al alcance e implementación efectiva de los derechos culturales. La información revisada abre múltiples expectativas hasta ahora inéditas en el país en cuanto a estos derechos y su irrefutable condición de derechos fundamentales.

\section{REFERENCIAS}

Arroyo, M. (2006). Los derechos culturales como derechos en desarrollo: una aproximación. Nuevas Políticas Públicas. Anuario multidisciplinar para la modernización de las Administraciones Públicas, 2, 262-283. Recuperado de http:// www.juntadeandalucia.es/institutodeadministracionpublica/anuario/articulos/ descargas/02_NOT_02_arroyo.pdf

Bayardo, R. (2010). Políticas culturales y derechos: entre la retórica y la realidad. RIPS. Revista de Investigaciones Políticas y Sociológicas, 9(2), 55-64. Recuperado de https://www.redalyc.org/articulo.oa?id=380/38017627005

De Castro, B. (1993). Los derechos económicos, sociales y culturales. Análisis a la luz de la teoría general de los derechos humanos. Secretariado de Publicaciones de la Universidad de León.

Champeil-Desplats, V. (2010). El derecho a la cultura como derecho fundamental. Revista Electrónica Iberoamericana, 4(1), 92-116. Recuperado de https://www.urjc.es/ images/ceib/revista_electronica/vol_4_2010_1/REIB_04_10_Veronique.pdf

Chanamé, R. (2015). La Constitución comentada (vol. 1). Lima: Ediciones Legales.

Colombato, L. (2012). Derechos culturales. Debilidades discursivas en la formulación de sus contenidos. Cuestiones transversales. Revista Perspectivas de las Ciencias 
Económicas y Jurídicas, 2(1), 81-100. http://dx.doi.org/10.19137/perspectivas2012-v2nla05

Comisión Mundial de Cultura y Desarrollo [UDSE]. (1996). Nuestra diversidad creativa. Informe de la Comisión Mundial de Cultura y Desarrollo. Recuperado de http://ibdigital.uib.es/greenstone/collect/cd2/import/nacionesunidas/onu0025.pdf

Cotler, J. (1987). Clases, Estado y Nación en el Perú (4. ${ }^{a}$ ed.). Lima: Instituto de Estudios Peruanos.

Custodio, T. (2014). Aproximación dogmática a los derechos culturales (el derecho a la cultura como derecho fundamental). Madrid: Instituto Interuniversitario para la Comunicación Cultural; Universidad Carlos III de Madrid, colección Cuadernos

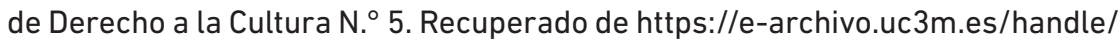
$10016 / 18206$

Donders, Y. (2004). El marco legal del derecho a participar en la vida cultural. En Derechos culturales y desarrollo humano (pp. 153-170). Madrid: AECID.

Fernández Sessarego, C. (1992). El derecho a la identidad. Buenos Aires: Astrea.

Harvey, E. (1995). Derechos culturales. Unesco. Recuperado de http://www2.congreso. gob.pe/sicr/cendocbib/con5_uibd.nsf/29123E3F329744B8052582820073C5F3/ \$FILE/DerechosCulturales.pdf

Häberle, P. (2000). Teoría de la Constitución como ciencia de la cultura. Madrid: Tecnos.

López, C. (1999). El patrimonio cultural en el sistema de derechos fundamentales. Secretariado de Publicaciones de la Universidad de Sevilla.

Los derechos culturales. Declaración de Friburgo. (2007). Recuperado de https://culturalrights.net/descargas/drets_culturals239.pdf

Marzal, M. (1978). Indigenismos y Constitución. Revista de la Universidad Católica, 3 , 69-97. Recuperado de http://repositorio.pucp.edu.pe/index/bitstream/handle/ 123456789/49164/indigenismo_constitucion_manuel_marzal.pdf?sequence=1

Mejía, J. L. (2004). ¿Derechos sin Estado? Tres momentos de la institucionalidad cultural en América Latina. Pensar Iberoamérica. Revista de Cultura, 7. Recuperado de https://www.oei.es/historico/pensariberoamerica/ric07a05.htm

Mesinas, A. (2017). Regímenes Internacionales, una herramienta teórica para comprender la implementación de los derechos culturales en México, ante la creación de la Ley General de Cultura. Cuicuilco. Revista de ciencias antropológicas, 24(68), 231-256. Recuperado de http://www.scielo.org.mx/scielo.php?script=sci_ arttext\&pid=S2448-84882017000100231\&lng=es\&tlng=es 
Meyer-Bisch, P. (1993). Les droits culturels, une catégorie sous-developpée des droits de l'homme. Friburgo: Éditions Universitaires.

Ministerio de Cultura. (2020). Política Nacional de Cultura al 2030. Recuperado de https:// cdn.www.gob.pe/uploads/document/file/1025961/PNC_VERSI\%C3\%93N_ FINAL_2.pdf

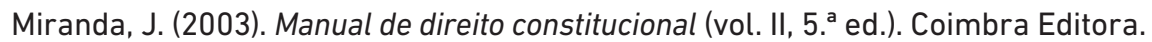

Miranda, J. (2010). Notas sobre cultura, Constitución y derechos culturales. Revista de Derecho Constitucional Europeo, 13, 47-66. Recuperado de https://dialnet.unirioja. es/servlet/articulo?codigo $=3411151$

Muñoz, A. (2018). Los derechos culturales: una categoría aún subestimada de derechos humanos. Anuario de Derechos Humanos, (14), 77-97. doi: 10.5354/07182279.2018.49162

Niec, H. (1998). Cultural right: at the end of the world decade for cultural development. En Intergovernmental Conference on Cultural Policies for Development, 30 de marzo al 2 de abril. Estocolmo, Suecia.

Organización de los Estados Americanos [OEA]. (30 de abril de 1948). Declaración Americana de los Derechos y Deberes del Hombre. Recuperado de https://www. oas.org/dil/esp/declaraci\%C3\%B3n_americana_de_los_derechos_y_deberes_ del_hombre_1948.pdf

Organización de las Naciones Unidas [ONU]. (10 de diciembre de 1948). Declaración Universal de Derechos Humanos. Recuperado de https://www.ohchr.org/EN/ UDHR/Documents/UDHR_Translations/spn.pdf

Organización de las Naciones Unidas [ONU]. (16 de diciembre de 1966). Pacto Internacional de Derechos Económicos, Sociales y Culturales de la Organización de las Naciones Unidas. Recuperado de https://www.ohchr.org/sp/professionalinterest/pages/ cescr.aspx

Organización de las Naciones Unidas [ONU]. (21 de diciembre del 2009). Observación General N. ${ }^{\circ} 21$ (2009). Derecho de toda persona a participar en la vida cultural (artículo 15, párrafo 1 a), del Pacto Internacional de Derechos Económicos, Sociales y Culturales.

Organización de las Naciones Unidas para la Educación, la Ciencia y la Cultura [Unesco]. (2001). Declaración Universal de la Unesco sobre la Diversidad Cultural. Recuperado dehttp://portal.unesco.org/es/ev.php-URL_ID=13179\&URL_DO=DO_TOPIC\&URL SECTION=201.html 
Organización de los Estados Americanos [OEA]. (noviembre, 2006). Carta Cultural Iberoamericana de Montevideo. Recuperado de https://www.segib.org/wp-content /uploads/Carta-cultural-iberoamericana.pdf

Pizzorusso, A. (1984). Lecciones de derecho constitucional (Trad. J. Jiménez Capo, vol. 1). Madrid: CEC.

Prieto de Pedro, J. (2008). Derechos culturales, el hijo pródigo de los derechos humanos. Crítica, 58(952), 19-24. Recuperado de http://www.revista-critica.com/administrator/components/com_avzrevistas/pdfs/8faba99a65f4110cf8e820c099f 65db8-952-Presente-y-futuro-de-los-derechos-humanos---marzo-2008.pdf

Stamatopoulou-Robbins, E. (2008). The right to take part in cultural life (documento de trabajo presentado al Comité de Derechos Económicos, Sociales y Culturales de las Naciones Unidas para su cuadragésima sesión, Ginebra). Recuperado de http://bit.ly/2CHFYVT

Symonides, J. (2010). Derechos culturales: una categoría descuidada de derechos humanos. Sala de Prensa. Web para profesionales de la comunicación iberoamericanos, 124(5). Recuperado de http://www.saladeprensa.org/art952.htm

Tajadura, J. (1998). La Constitución cultural. Revista de Derecho Político, 43, 97-134. Recuperado de http://e-spacio.uned.es/fez/eserv.php?pid=bibliuned:DerechoP olitico-1997-43-13760\&dsID=PDF

Torres del Moral, A. (1984). Artículo 44. En Comentarios a las Leyes Políticas. Constitución Española de 1978 (tomo IV, p. 210). Madrid: Editorial Revista de Derecho Privado, Edersa.

Van Boven, T. C. (1984). Estudio de derecho internacional positivo sobre derechos humanos. En K. Vasak (Ed.), Las dimensiones internacionales de los derechos humanos (vol. 1, p. 136). Barcelona: Serbal; Unesco.

Zierer, E. (1992). Las minorías lingüísticas en la Constitución Política del Perú. En Doctrina constitucional (pp. 227-236). Trujillo: Instituto de Divulgación y Estudios Jurídicos Constitucionales. 